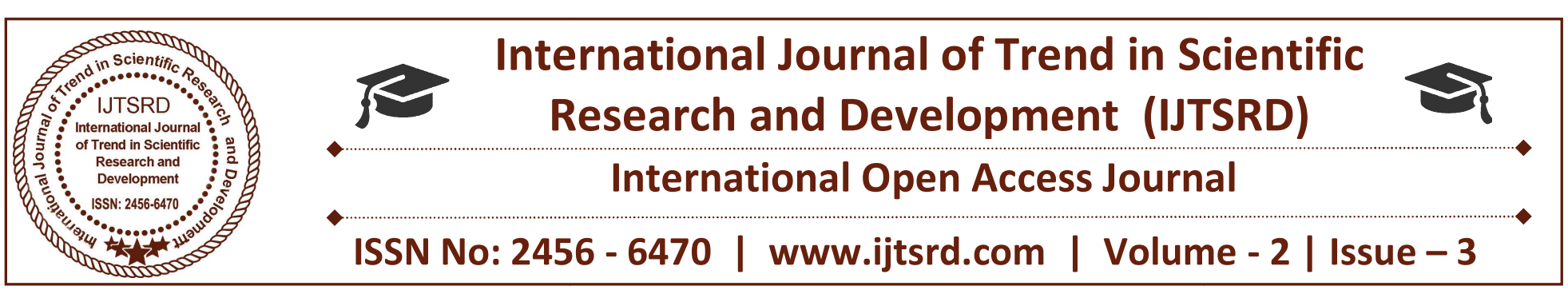

\title{
A Review of Development Centrifugal Pump Testing Setup According to IS 9137 -1978 Standard
}

\author{
Rathod Rohinkumar B \\ PG Fellow, Dept of Mech. \\ Engineering, Parul Institute of \\ Technology, Vadodara, India
}

\author{
Jain Khushbu \\ Professor, Dept of Mech. \\ Engineering, Parul Institute of \\ Technology, Vadodara, India
}

\author{
Shah Maitrik \\ Assistant Professor, Dept of Mech. \\ Engineering, Marwadi College of \\ Technology, Rajkot, India
}

\begin{abstract}
Centrifugal pump finds vast application in the industry. In this research paper try to developed the laboratory testing setup for measuring the major parameters of the centrifugal pump which - are mentioned in the each and every contractual condition between the manufacturer's and purchaser.
\end{abstract}

Keywords: Centrifugal pump, efficiency, ISO standard, test rig setup, hydrostatic testing

\section{INTRODUCTION}

The centrifugal pump have found very large application at industries and commercial application at particular field like oil and gas industry, buildings, agriculture and irrigation work, steam power plant, paper and pulp industry. These enable fluid transmission between two places by utilizing power from some other external source. Centrifugal pumps belong to dynamic pressure pumps that generate head and flow by increasing the velocity of the liquid with the help of a rotating vane impeller followed by a diffuser. Specific speed, blade orientation, casing insulation, impeller diameter, number and pitch of blades, surface finish of the internal surfaces, viscosity of fluid etc. are the parameters that influence the performance of such pumps.
The hydraulic energy is in the form of pressure energy if the mechanical energy is converted into pressure energy by means of centrifugal force acting on the fluid, the hydraulic machine is called centrifugal pump. The centrifugal pump act as a reserved of inward radial flow reaction turbine. This means that the flow in centrifugal pumps is in the radial flow reaction turbine. This means that the flow in centrifugal pumps in the radial outward direction. The centrifugal pump work on the principle of forced vortex flow which means that "when a certain mass of liquid is routed by an external torque, the rise in pressure head of rotating liquid takes place" . The rise in pressure head at any point of the rotating liquid is proportional to the square of tangential velocity of the liquid at the point. Thus at the outlet of the impeller where radius is more, the rise in pressure head. Due to this high pressure head, the liquid can be lifted to a high level.

The general component of centrifugal pumps is listed below.
I. Suction pipe
II. Impeller
III. Casing
IV. Delivery pipe 
Flow chart 1 General components of the centrifugal pump

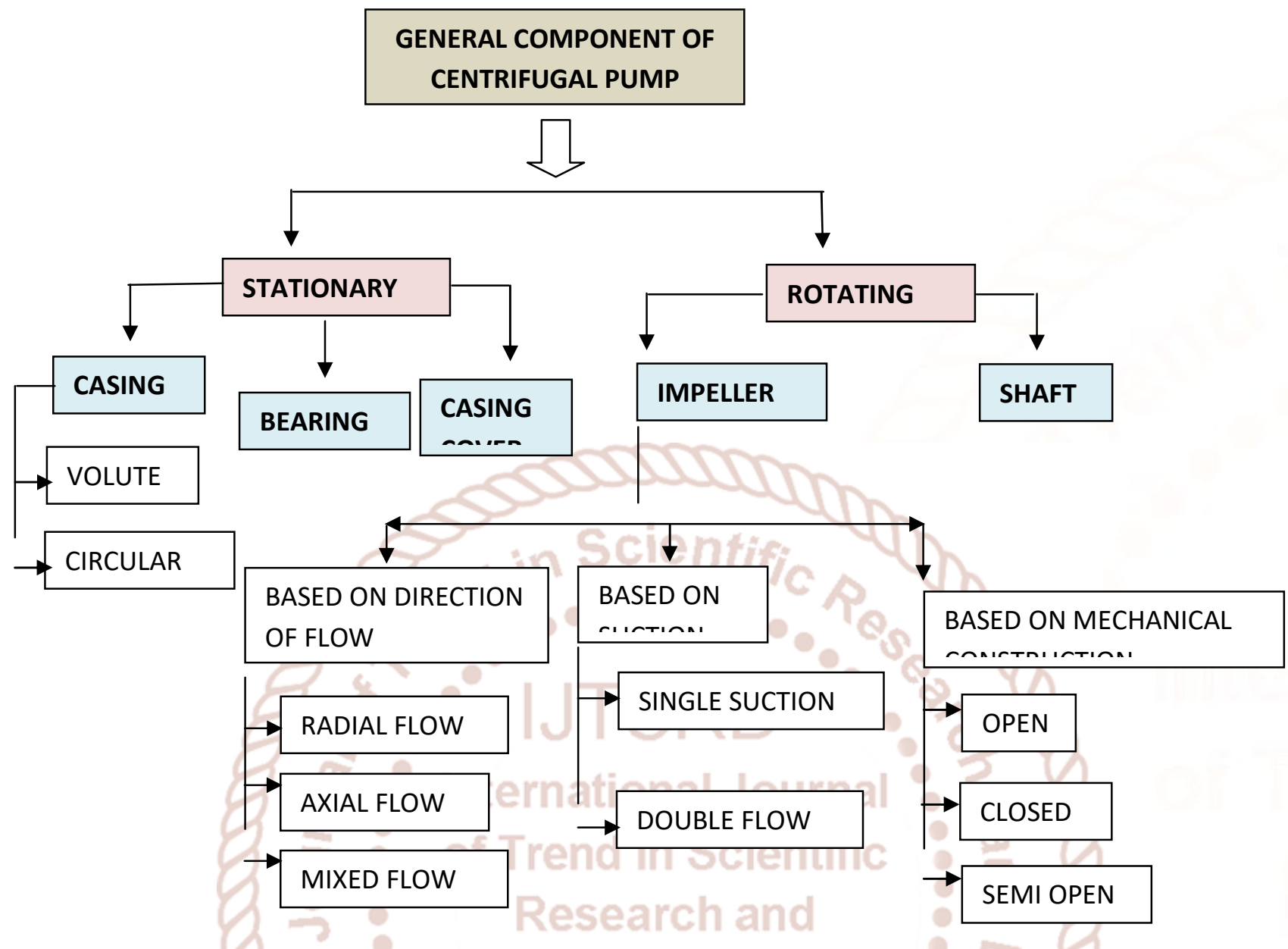

\section{Concept behind development of the testing setup according to is standard}

The major advantage of developing testing setup according to the standard is that after final assembly when it is checked and if some parameters are not match according to the design criteria than at that time we can change the problem at its initial stage otherwise if testing setup is not accurately work than not get exact idea behind the product failure.

And the major advantage is at each and every industry the pump is tested and delivered at the different location. The pump after dispatch from the industry operated at the different condition in which there is not actually designed or fabricated. So the result under which condition it is operated must be applicable to the result under which it is tested. But there is vast difference between the operating condition and the testing condition so before the limit of the guarantee point of the pump it will be failure.
III. TEST RIG SETUP

'Test-Rig is an apparatus used for assessing the performance of a piece of mechanical or electrical equipment '.Test rig for the testing of the centrifugal pump is an arrangement of the various elements like piping system, gauges, valves etc. used to measure various flow parameters of the pump like pressure, flow rate, efficiency etc. Test rig can measure more than one parameters at a time and saving time.

This Indian standard adopted by the Indian Standard Institution on 18 Dec 1978 after the draft finalized by the Pumps Sectional Committee had been approved by Mechanical Engineering Division Council. This Standard is one of a series of Indian Standard dealing with the acceptance test for centrifugal, mixed flow and axial pumps. These standards would correspond to three classes of test $\mathrm{A}, \mathrm{B}$ and $\mathrm{C}$; the use of class $\mathrm{A}$ and $B$ is restricted to special cases when there is a need to have the pump performance more precisely defined. Pump performance may be effected by conditions of the final site installation and procedure 
are describes for carrying out standard test on certain types of installation of which an overall performance is required.

For development of the testing it is majorly concern about two to three parameters of the centrifugal pump which are mentioned in the contractual condition between the manufacturer and purchaser. The major parameter which are consider in the contractual condition are head, flow, and pressure.

Normally for the better arrangement the pipe used for the testing setup is selected always one size larger than the commercial size available in the market so the fluid can passed easily form the piping system.

For measuring the pressure two different pressure gauges are used at suction and discharge sides. The testing setup is open well testing setup so the operating fluid is directly sucked by the open tank which is directly open to the atmosphere. So the fluid pressure at suction side is lower than the atmospheric pressure so the suction side as a pressure measuring device vacuum gauge is used . Normally the vacuum gauge is installed at the two times distance of the inlet diameter of the centrifugal pump. At that distance the vacuum gauge is installed and the hole of the same diameter of the gauge is done into the pipe. The leg is dipped into the pipe at the twice times of the diameter of the leg so the fluid can make appropriate contact with the working fluid and measure the exact valued of the pressure.

While for the discharge the pressure range is always higher than the atmospheric value so at that side the pressure gauge is used and fitted at the twice diameter of the discharge side of the pump.

While the flow meter is always installed at the four times of the diameter of the pump suction side from the installation of the pressure gauge or vacuum gauge. Because if the distance is less than it than the flow which comes into the contact with the pressure gauge have turbulence property and not get exact result. So if distance maintains 4D or more than it than between this distance the flow may be convert from turbulence to laminar.

The foot valve is installed at the $500 \mathrm{~mm}$ distance from the bottom side of the tank so that the turbulence generated during suction not affect the performance of the centrifugal pump. And the surface of the water which are top to the viewer may remain stable so if any kind of error generated in any other device than identified easily.

The suction and discharge pipe are also if installed in the same tank than the distance between the two fluid lines are more than six times of the diameter (6D) so when the discharge line release fluid back to the tank than whirls are generated which are not affect the suction pipe line and the fluid easily sucked from the tank.

In fig indicated the model of pump $100-80-165$. Which indicate the pump having $100 \mathrm{~mm}$ suction side dia $80 \mathrm{~mm}$ discharge side dia. and $165 \mathrm{~mm}$ is impeller nominal dia. 


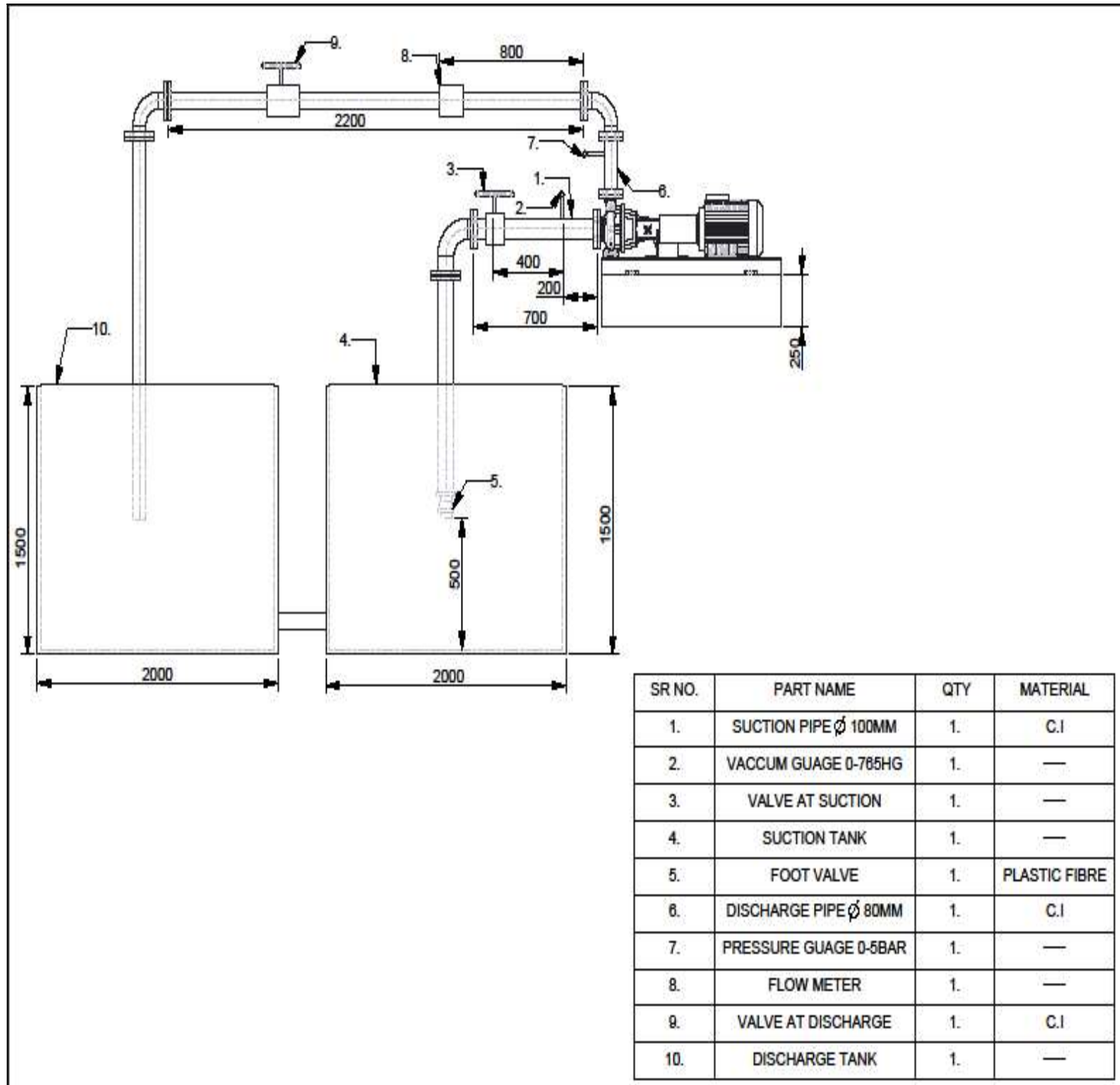

Fig 1.1 Testing setup of centrifugal pump acc to IS 9137

\section{Acceptance of accuracy variation in measurement}

Any device or method which by calibration or comparison has been demonstrated to be capable of measuring with systematic errors not exceeding the limit in the following table may be used. The devices or methods shall be agreed upon by both parties concerned.
Table 1 Maximum Permissible Limit Of Overall Errors

\begin{tabular}{|l|l|}
\hline Quantity & Permissible limit \\
\hline $\begin{array}{l}\text { Rate of flow } \\
\text { Pump total head } \\
\text { Pump power input } \\
\text { Electrical power input }\end{array}$ & 3.5 \\
\hline Speed of rotation & 2.0 \\
\hline $\begin{array}{l}\text { Overall efficiency } \\
\text { (computed from the } \\
\text { rate of flow total } \\
\text { head and electrical } \\
\text { power) }\end{array}$ & 4.5 \\
\hline Pump efficiency & 5.0 \\
\hline
\end{tabular}




\section{LITERATURE REVIEW}

A literature review surveys scholarly articles, books, dissertations, conference proceedings and other resources which are relevant to a particular issue, area of research, or theory and provides context for a dissertation by identifying past research. Various research papers were reviewed regarding my project "Hydrostatic testing of centrifugal pump and testing setup rig according to ISO standard" as follows.

R. Hirschi studied the effect of the cavitations on the efficiency of the pump. In this paper he identified that there are mainly two kind of cavitations take place one is leading edge cavitations and second is bubble cavitations. The leading edge cavitation is mainly dependent on the geometry of the impeller blade because when fluid enter into the casing the centrifugal force acting on it and make it to go radially outward so the fluid guided by impeller blade and flow separation take place at the tip of the impeller. While at any point due to law pr. Up to vapour pr. If generating than bubble formation take place at that point and this bubble travelling to casing by radially outward direction and when high pr. Region come they will collapsed and generate high pr. On the casing wall. In this research paper he did CFD analysis on the finding where the high pr region is identified. For solving this kind of problem suggest some ideas by increasing the thickness of the casing at the point where the cavitations take place is the one way to increase the life of the pump. By changing the geometry of the impeller blade can also help to minimize the cavitation effect by changing the tip of the blade in to sharp bullet shape the flow separation time will delay and it is help to improve the efficiency of the pump. By Thomas cavitation number one can find the height at which cavitation take place manually. While the design operating point such as bubble cavitation and hub cavity and this is very sensitive to THOMA'S CAVITATION FACTOR.

B. Jafarzadeh identified that the efficiency also depend on the path followed by the fluid. For this kind of problem fluent is used in which the fluid rotates around an axis as fluid rotates inside of the casing. It works on pr. Distribution and power consumption by system. For minimizing this kind of the arising problem one can work or modify the parameter like redesign the impeller blade, shroud, inlet duct because this are the major parts where fluid interact widely. The position of the blade compare to the tongue of the volute is also plays and important role because the separation is start from this point.(same tongue position) For larger distance between blade and tongue flow separation has begun later. By CFD analysis power consumption reduce almost from $8 \%$ to $8.7 \%$.

Kotakar Sandeep Gulabrao suggested that the exits angle of the impeller also very important and a major parameter for effecting the characteristic of the pump. The blade exist angle have significant effect on head and efficiency of the pump. By increasing the impeller angle also energy lost at local region severely but decreasing the angle improves wear capacity and efficiency also. For this kind of analysis done in FLUENT CFD. Where pump is divided into three regions from which two are static namely inlet portion and outlet portion while other one has correlate with blade which has rotational speed.

Wang Yuchuan suggested one way to improve the efficiency of the centrifugal pump by providing inner guide vane in between the path of flowing fluid. Mainly used when during operation slight variation of pr. require while same rotational speed .For this CFD code CFX module is used in which frozen rotor and transient rotor stator method are used. IGV(inner guide vane)used to modify the flow which increase static efficiency and reduce power consumption. At small IGV angle there is no difference between the model without IGV and model having IGV. But at large angle it effect very sharply. For large angle it generates blockage of the flow at suction portion so that there is very high transient flow generating during operation and vibration also generated.

Peng Guangjie studied that from crack generation to failure of the centrifugal pump is due to stress concentration formation around the ribs provided on the pump. To provide limitation on the pump cover deformation, casing provided with the outer radial ribs. And this rib becomes the reason for generating stress concentration. So in this case stress concentration is unavoidable. So try design pump without radial ribs. Pump installation requires that the distance between the centre of the pump and the pump bottom is minimum. So make the bottom portion of the pump flattened and ribs covering in bottom region minimize their size also. It is also observed at the interface of the volute shaped body and casing \& angular distance to discharge nozzle to the suction pipe. To minimize stress concentration into this area 
during provides additional thickness in this area. For any kind of the change in design model check into ANSYS software and check the stress generated.

Tarang Agarwal suggested that if we use the pump into reverse manner than we can use its pressure energy for generation of the mechanical energy. If centrifugal pump is operated in reverse mode than it convert pr. Energy and kinetic energy into mechanical energy OR works as a turbine. The PAT works at high head and high flow rate compare to pump it produce same efficiency. While this two parameters are depend on the specific speed of the impeller. For more efficiency the shape of impeller also modified and if flow of water capacity is increased after modification than power extracted from turbine is also increased. PAT generates high shaft revolution around $1500 \mathrm{rpm}$ which is enough to directly joined without speed reduction gear. There is no change due to the variation into the flow capacity so that it can used at variation load condition. Only medium range of centrifugal pump give sufficient amount of efficiency while low and high speeds are still need to analyzed. When industry is not capable for purchasing the new one power grid unit at that time by using 4 to 5 pump we can make a system which generates electiricity.

P. Hergt The small displacement of rotor from the centre of the base circle can cause to generate the large amount of the radial forces which is the reason behind to generate noticeable change into casing under this eccentric load condition. For avoiding this small radial force developing centrifugal pump made and used stiffed shaft

Naveen Sharma studied the test rig setup of centrifugal pump which is able to investigate parameters and also use more than one pump used at a time. There are three main sources from where radial force generated circumferential change in volute pressure Leakage flow between impeller discharges to inlet portion no uniformity in momentum flux out of the impeller. The present work was undertaken with the objective of detailed investigation of the centrifugal pumps performance when operated in different conditions either individually or in combinations of series or parallel. The evaluated results have been presented in graphical form for variation of Head, Input power and Efficiency with flow rate (Discharge). From this study, an insight about the characteristics of centrifugal pump and their behavior corresponding to different conditions and combinations has been examined.

\section{CONCLUSION}

The present work has undertaken with the objectives of the understanding the proper installation of the measuring devices for measurement of the accurate data. And give some basic understanding for the testing of the centrifugal pump under the IS standard observation criteria. Also help to validate that for any pump which is fabricated according to IS standard than it is able to fulfilled the all criteria relating to its dimension as well as all measuring parameters are under the permissible limits or not. If the measuring parameters like head, efficiency power absorption etc are within the permissible varying limit of parameter or not. The main objective will achieve during this experimental work is making Laboratory class testing of Centrifugal End Suction Pump with range of 25 to $450 \mathrm{~m} 3 /$ hour of Discharge and up to 100 meter of height.

\section{REFERENCES}

1. Indian Standard Code For Acceptance Test For Centrifugal Mixed Flow And Axial Flow Pump ( IS 9137 - 1978).

2. Universal test rig concept for centrifugal and positive displacement pumps by Mathians bode Elsevier Vol 1996 Issue 354 march 1996.

3. "Introduction to cavitation in hydraulic machinery" by François AVELLAN The 6th International Conference on Hydraulic Machinery and Hydrodynamics Timisoara, Romania, October $21-22,2004$

4. "Parametric Study and Design Optimization of Centrifugal Pump Impeller" by Vijaypratap R Singha, M J Zinzuvadiaa, Saurin M. Shethb at ISSN : 2248 - 9622 vol. 4 issue 1 January 2014.

5. "Review of Pump as Turbine (PAT) for MicroHydropower " by Tarang Agarwal at International Journal of Emerging Technology and Advanced Engineering ISSN 2250-2459, Volume 2, Issue 11, November 2012 .

6. Experimental study of characteristic curves of centrifugal pumps working as turbines in different specific speeds by Shahram Derakhshan *, Ahmad Nourbakhsh science direct Experimental Thermal and Fluid Science 32 (2008) 800-807. 
7. Experimental Work on Modification of Impeller Tips of a Centrifugal Pump as a Turbine by Made Suarda*, Nengah Suarnadwipa and Wayan B. Adnyana The 2nd Joint International Conference on "Sustainable

8. Strength analysis of a large centrifugal dredge pump case Peng Guangjie a,1, Wang Zhengwei a, ${ }^{*}$ Yan Zongguo a, Liu Ruixiang elsevier Engineering Failure Analysis 16 (2009) 321-328.

9. Centrigual pump by Johann F Guluich

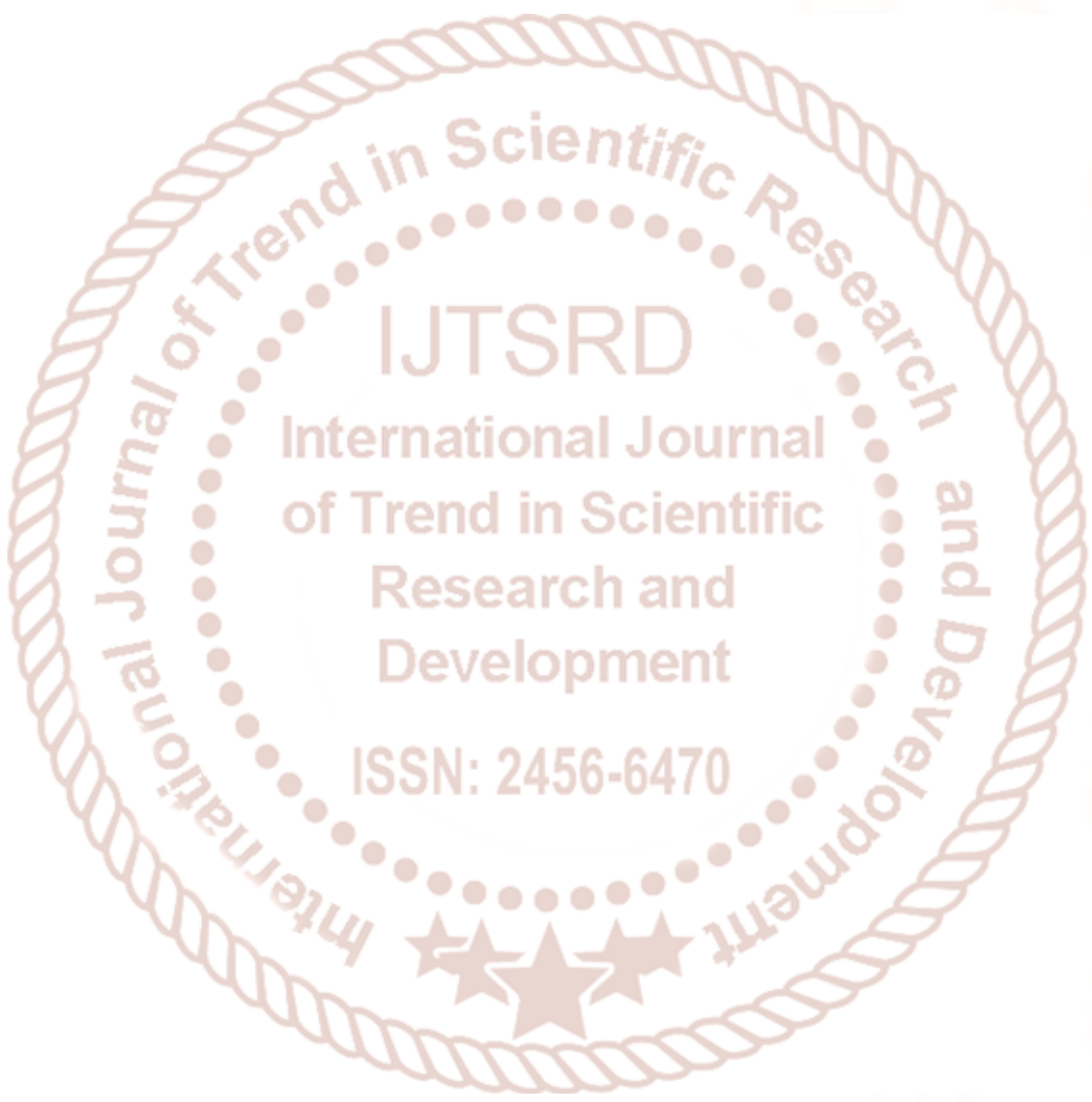

